\title{
Pesquisas Sociogeolinguísticas e a variável faixa etária em estudos no estado de São Paulo
}

\begin{abstract}
Adriana Cristina Cristianini ${ }^{1}$
Resumo: Os estudos sociogeolinguísticos, mais que apresentar um rol de designações por meio dos atlas, retratam a cultura, as crenças, as memórias e o modo de ver o mundo dos integrantes de uma comunidade linguística em dado espaço geográfico, numa determinada época. Apesar de se tratar de estudos de determinada etapa sincrônica, essas pesquisas também revelam aspectos que se reportam à atualização do léxico num processo de mudança linguística e à compreensão das subjacências presentes a cada designação. Este trabalho tem como objetivo: (i) discutir os fatores que justificam a adoção do termo Sociogeolinguística; (ii) propiciar reflexão sobre a natureza da relação entre léxico e aspectos sócio-cultural-histórico-ideológicos de grupos sociais numa determinada época; (iii) verificar os itens lexicais em que se pode observar mudança em curso por meio de evidência de variação diageracional.

Palavras-chave: Sociogeolinguística; léxico; variação e mudança linguística; São Paulo.
\end{abstract}

Abstract: Sociogeolinguistic studies present more than a list of meanings by the atlas, they portrait culture, beliefs, remembrances and the way people of a linguistic community see the world in a specific geographic area, in a given time. Although they are a sort of synchronic study, these researches also reveal aspects that report to lexical updating on a linguistic changing process and to the understanding of each designation underlays. The purposes of this work are: (i) to discuss the factors that justify the adoption of the term Sociogeolinguistic; (ii) to offer a reflection about the nature of the relation among lexis and social, cultural, historical and ideological aspects of social groups in a given time; (iii) to verify the lexical items in which we can observe ongoing changes by the evidence of diagenerational variation.

Keywords: Sociogeolinguistic; lexicon; linguistic change and variation; São Paulo.

\section{Considerações iniciais}

A língua é o principal elemento de interação social e os sentidos se dão nessa interação entre sujeitos que estão situados num determinado tempo, num certo espaço, inseridos num dado grupo e atuando baseados num contexto específico. Esses sujeitos carregam a ideologia da comunidade da qual fazem parte e trazem consigo crenças, costumes, valores culturais, sociais. Portanto, iniciar qualquer discussão linguística,

\footnotetext{
${ }^{1}$ Doutora em Linguística pela Faculdade de Filosofia, Letras e Ciências Humanas da Universidade de São Paulo - FFLSH/USP; professora do Instituto de Letras e Linguística - Ileel, da Universidade Federal de Uberlândia - UFU.
} 
atualmente, sem considerar que a língua está relacionada aos aspectos culturais da comunidade e, consequentemente, aos usuários da língua, é inconcebível.

Visualizar as relações entre o ambiente geográfico e a distribuição espacial dos fenômenos linguísticos, verificando-se a norma diatópica da localidade, tem sido uma constante em estudos que se norteiam pelos preceitos da "Geolinguística". Contudo, nas últimas décadas, a necessidade de uma nova abordagem científica tem sido discutida de forma que o conhecimento - antes estruturado em bases consideradas rígidas, em blocos sólidos - possa ser visto como uma teia em que tudo está interligado.

Segundo Morin (2001, p. 73),

Essa visão nos leva a compreender o mundo físico como uma rede de relações, de conexões, e não mais como uma entidade fragmentada, uma coleção de coisas separadas. Se separarmos as partes, se as isolarmos do todo, estaremos eliminando algumas delas na tentativa de delinear cada uma. Portanto, não existem partes isoladas.

Diante disso, apesar dos estudos geolinguísticos, há algum tempo, se preocuparem com a análise das variações diatópicas levando em consideração determinadas variáveis sociais - idade, gênero e escolaridade - alguns estudiosos cunharam o termo Sociogeolinguística para classificar estudos que lançam mão de outras variáveis que atuam nos usos, costumes, fenômenos linguísticos.

Para a Sociogeolinguística, é essencial ressaltar que os resultados, coletados por meio da aplicação de questionários para a elaboração do atlas (prática comum em estudos geolinguísticos), são registros da interação que ocorre no momento da pesquisa. Isso se constata, inclusive, se considerarmos as notas que, em alguns atlas, são apresentadas com informações sobre o comportamento dos sujeitos na interação com o pesquisador.

O presente trabalho está norteado pelos seguintes objetivos: (i) discutir os fatores que justificam a adoção do termo Sociogeolinguística; (ii) propiciar reflexão sobre a natureza da relação entre léxico e aspectos sócio-cultural-histórico-ideológicos de grupos sociais numa determinada época; (iii) verificar os itens lexicais em que se pode observar mudança em curso por meio de evidência de variação diageracional. 
Far-se-á, para tanto, um cotejamento entre os resultados e análises de alguns estudos concluídos e em andamento sobre o uso lexical na Língua Portuguesa falada no Brasil. Dar-se-á ênfase a estudos realizados: na região do Grande ABC Paulista; em municípios do Litoral Norte do estado de São Paulo; e no município de Iguape.

Esses trabalhos foram desenvolvidos por integrantes do Grupo de Pesquisa em Dialetologia e Geolinguística, da Universidade de São Paulo - GPDG/USP. O grupo, além de outras atividades, desenvolve o projeto coletivo "Estudo sociogeolinguístico do município de São Paulo: o léxico - parte II", que visa à elaboração de um banco de dados do léxico do português falado no município de São Paulo, do ponto de vista sociogeolinguístico, em cinco pontos do município, correspondentes às cinco regiões da cidade de São Paulo.

\section{A Sociogeolinguística}

A Sociogeolinguística ocupa-se de desenvolver estudos vinculados à variação linguística de caráter predominantemente diatópico. Por tratar-se de um trabalho em que se aplica um questionário a um conjunto de sujeitos com características específicas em uma rede de pontos e em que os resultados recebem tratamento quantitativo e qualitativo para a criação de um banco de dados que, depois, possibilita a apresentação dos resultados em quadros, tabelas e cartogramas, tem-se a ideia de que os estudos sociogeolinguísticos tratam exclusivamente de estudos sincrônicos. Acrescenta-se a isso o fato de, visto que as entrevistas são realizadas em um tempo específico e são analisados os fenômenos linguísticos constatados na época da coleta de dados.

Entretanto, apesar de se realizar uma pesquisa com uma perspectiva sincrônica, um olhar diacrônico no recorte espacial estudado é possível e pertinente. Diante dessas análises, a Sociogeolinguística dispõe-se, além de desenvolver estudos da variação diatópica, a contribuir para o estudo da história da Língua Portuguesa no Brasil.

As disciplinas separam os conhecimentos. Aprendemos a analisar, a separar, mas não aprendemos a fazer com que esses conhecimentos se comuniquem, se relacionem. 
No século XVII, René Descartes - principal representante do Racionalismo propõe as seguintes bases para o estudo científico:

1. não aceitar nada que não seja evidente e evitar a prevenção e a precipitação - só vale o que for provado cientifico e racionalmente;

2. dividir um problema em tantas partes quantas forem possíveis e necessárias, a chamada regra da análise;

3. conduzir o pensamento por ordem, partindo dos objetos mais simples para os mais complexos, a chamada regra da síntese;

4. efetuar enumerações tão completas de modo a ter certeza de nenhum elemento ter sido esquecido.

No século XX, contudo, Edgar Morin - hoje considerado um dos maiores expoentes do pensamento mundial - propõe uma mudança de ótica diante do conhecimento.

Morin (2000) propõe o "pensamento sistêmico", que pode ser entendido como uma nova forma de abordagem a qual defende que todos os elementos influenciam e são influenciados reciprocamente. Nessa abordagem, o homem é visto não apenas como um indivíduo isoladamente, mas também são considerados seu contexto e as relações nele estabelecidas.

Para pensar sistematicamente, é necessária uma nova forma de olhar o mundo, de olhar o homem e, consequentemente, uma mudança de postura por parte do cientista.

A união das partes, a soma das partes, para Morin (2000), não resulta necessariamente no todo. Aliás, é importante que se tenha uma visão do todo para compreender as partes.

Segundo Moraes (2001, p. 73),

Essa visão nos leva a compreender o mundo físico como uma rede de relações, de conexões, e não mais como uma entidade fragmentada, uma coleção de coisas separadas. Se separarmos as partes, se as isolarmos do todo, estaremos eliminando algumas delas na tentativa de delinear cada uma. Portanto, não existem partes isoladas.

Estudos realizados perante uma abordagem sistêmica pressupõe: 
1. a junção da complexidade dos conhecimentos científicos com os conhecimentos não-científicos, tradicionais do povo;

2. a condenação das formas convencionais dos saberes, divididos em disciplinas que fragmentam o conhecimento em partes segmentadas e estanques;

3. as questões de natureza ética, estética e socioambientais colocadas em posição de prioridade;

4. a integração da interdisciplinaridade na pesquisa e na ampliação de saberes/práticas dos sujeitos da sociedade com saberes/práticas dos pesquisadores.

O Grupo de Pesquisa em Dialetologia e Geolinguística, da Universidade de São Paulo - GPDG/USP, há alguns anos, tem nomeado Sociogeolinguística os estudos dialetais que consideram tanto a variável diatópica quanto as variáveis sociais e, diante disso, as variáveis culturais, as variáveis psicológicas, as variáveis espirituais etc.

O termo Sociogeolinguística foi cunhado, segundo Cristianini (2012), tomandose a mesma regra de formação de palavras que ocorre em Geolinguística, em que o elemento antepositivo acrescentado ao substantivo "linguística" amplia/modifica o significado do nome. Ao acrescentarmos o antepositivo determinador soci(o)- ao substantivo, já cristalizado, Geolinguística, ampliamos/modificamos o significado deste, pois, para o estudo sociogeolinguístico, mantemos os preceitos da Geolinguística, mas analisamos também as relações socioculturais que influenciam o comportamento geolinguístico dos sujeitos.

Conforme afirmam Cristianini e Encarnação (2009,p.91):

O termo Sociogeolinguística surge, no florescer do século XXI (em 2004), empregado inicialmente pelo Grupo de Pesquisa em Dialetologia e Geolinguística da Universidade de São Paulo GPDG/USP - para designar os estudos geolinguísticos que consideram fatores tanto geográficos quanto sociais para coleta, registro e análise de dados linguísticos. 
Para a Sociogeolinguística, é essencial ressaltar que os resultados, coletados por meio da aplicação do questionário para a elaboração do atlas, são registros da interação que ocorre no momento da pesquisa. É nessa interação entre os sujeitos que se dão os sentidos. Além disso, os sujeitos fazem parte de um grupo, num determinado tempo e espaço, que circunscreve ideologias, costumes, crenças, valores, e estes são acionados no momento da interação.

De acordo com Santos (2009),

Um atlas linguístico deve prever, pelo menos, dois interlocutores. De um lado, um sujeito/autor produz um texto que se propõe a revelar a complexidade da variação linguística de cunho diatópico de grupos sociais, em papel e/ou em meio eletrônico. De outro, um sujeito/leitor o examina, buscando interpretar os elementos que o sujeito/autor tencionou mostrar. Como se pode observar, o binômio produção/interpretação embasa o movimento que leva os dois sujeitos - autor e leitor - à (re)construção dos vários sentidos de um fenômeno linguístico, qual seja, a variação linguística subjacente ao saber/fazer geolinguístico. Dito em outras palavras, um atlas linguístico é um texto que dá origem a vários outros textos.

\section{Análise dos dados}

Para este trabalho, tomamos como base os seguintes estudos:

1. Atlas semântico-lexical da região do Grande ABC (CRISTIANINI, 2007);

2. Estudo sociogeolinguístico do município de Iguape: aspecto semântico-lexical (SILVEIRA, 2009);

3. Atlas semântico-lexical de Caraguatatuba, Ilhabela, São Sebastião e Ubatuba: municípios do Litoral Norte de São Paulo (ENCARNAÇÃO, 2010).

Os três trabalhos criam possibilidade de comparação por terem sido realizados partindo da mesma base metodológica. Nos três casos, a composição do corpus foi feita por meio da aplicação de um questionário semântico-lexical cujas questões, na sua grande maioria, eram iguais. Os sujeitos entrevistados também apresentam, nos três estudos, um perfil similar, a saber: sujeitos de baixa escolaridade, dois gêneros 
(masculino e feminino) e duas faixas etárias (de 18 a 30 anos e de 50 a 65 anos de idade). Além disso, os pesquisadores montaram um banco de dados com os resultados obtidos na pesquisa e procederam uma análise quantitativa e qualitativa das respostas dos sujeitos ao questionário.

Considerando sujeitos de diferentes faixas etárias, percebe-se que há itens lexicais que aparecem predominantemente entre sujeitos da primeira faixa etária e outros, entre sujeitos da segunda faixa etária. Podemos inferir, portanto, que há uma mudança em curso do item onomático relacionado à designação em questão.

Daremos destaque a algumas questões para ilustrar nossa teoria. Aos sujeitos da pesquisa foi apresentada a questão como se chama “... tronco, pedaço de pau ou tábua que serve para passar por cima de um (cf.item 1)?". Cabe aqui esclarecer que a lacuna na questão deve ser preenchida pelo pesquisador conforme a resposta dada pelo sujeito à questão anterior, que é como se chama “... um rio pequeno de uns dois metros de largura?".

$\mathrm{Na}$ região do Grande $\mathrm{ABC}$ paulista, temos como resposta à questão o item lexical "ponte", com maior frequência nos resultados, seguido dos itens lexicais: "pinguela", "passarela", "apoio", "árvore”, "gambiarra" e "viela".

Podemos verificar no gráfico a seguir as frequências obtidas na pesquisa:

Gráfico 1 - Frequência

\begin{tabular}{|c|c|c|c|c|c|c|c|}
\hline \multicolumn{8}{|l|}{80} \\
\hline \multicolumn{8}{|l|}{40} \\
\hline \multicolumn{8}{|l|}{20} \\
\hline U & ponte & pinguela & passarela & apoio & árvore & gambiarra & viela \\
\hline$\square$ absoluta & 23 & 7 & 2 & 1 & 1 & 1 & 1 \\
\hline$\square$ relativa (\%) & 63,89 & 19,44 & 5,56 & 2,78 & 2,78 & 2,78 & 2,78 \\
\hline
\end{tabular}


O item lexical "ponte", conforme podemos observar no cartograma 2 do Atlas semântico-lexical da região do Grande $A B C$, constitui-se em norma na região do Grande $\mathrm{ABC}$, pois possui alta frequência e distribuição regular, estando presente em todos os pontos da pesquisa.

Cartograma 2 - PINGUELA - Atlas semântico-lexical da região do Grande ABC

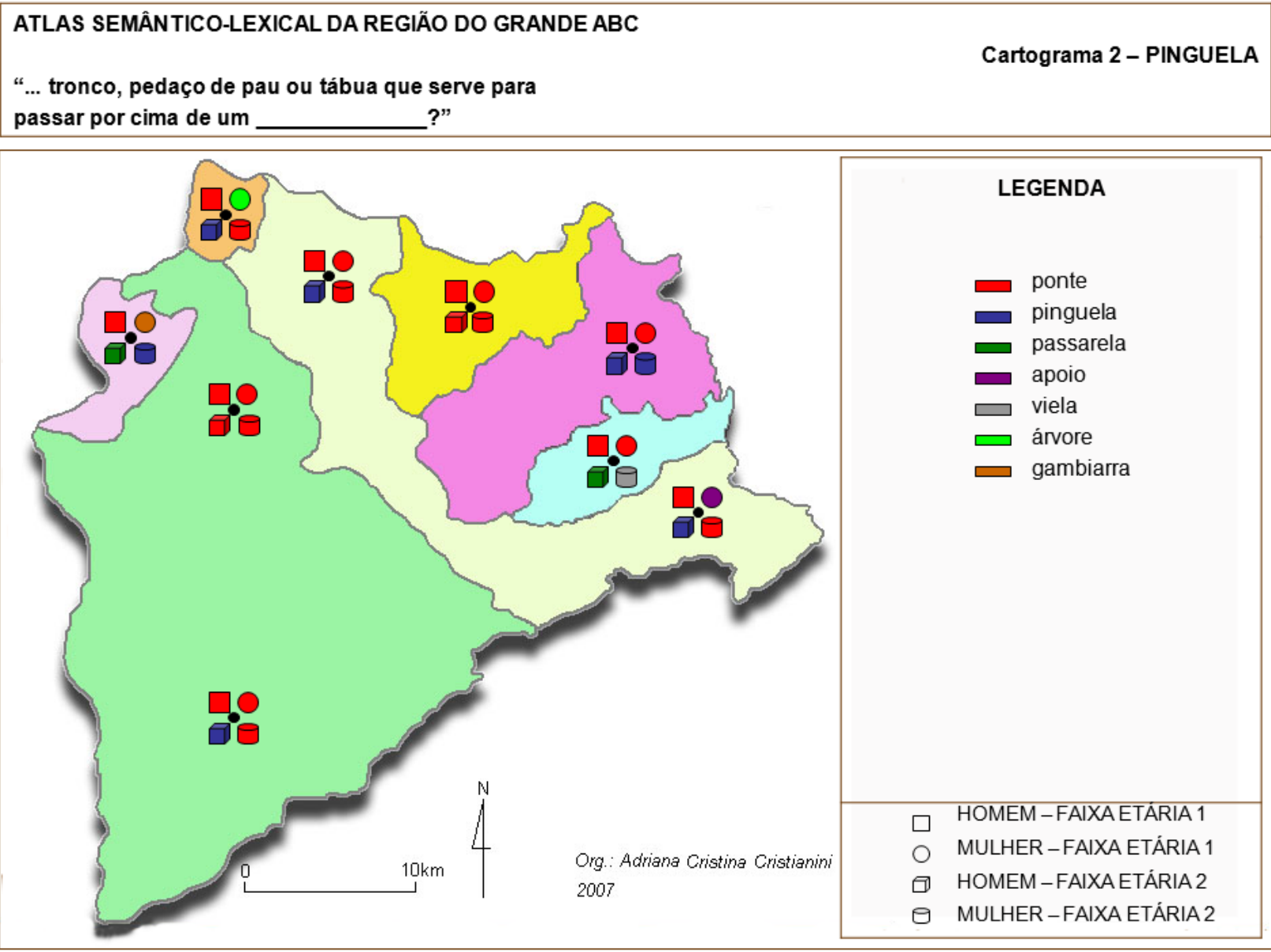

Cabe observar que é relevante a constatação de que o item lexical "ponte" aparece com maior frequência entre os sujeitos da faixa etária 1, enquanto o item lexical "pinguela", segunda maior frequência de respostas para a questão, é registrada exclusivamente entre os sujeitos da faixa etária 2 , como podemos verificar na tabela a seguir: 


\begin{tabular}{ccccc}
\hline & \multicolumn{2}{c}{ "ponte" } & \multicolumn{2}{c}{ "pinguela" } \\
& Ocorrência & $\%$ & ocorrência & $\%$ \\
\hline Faixa etária 1 & 15 & 65,22 & 0 & 0 \\
Faixa etária 2 & 8 & 34,78 & 7 & 100 \\
\hline Total & 23 & 100 & 7 & \\
\hline
\end{tabular}

No Litoral Norte do estado de São Paulo, encontramos o mesmo fenômeno ao observarmos as respostas à questão: como se chama “... tronco, pedaço de pau ou tábua que serve para passar por cima de um (cf.item 1)?"

Nessa região, "ponte" $(81,25 \%)$ constitui-se em norma da região e também houve a resposta "pinguela" (12,5\%), exclusivamente na segunda faixa etária. Uma outra variação foi registrada na pesquisa realizada no Litoral Norte, "tronco" (6,25\%).

Encontramos um exemplo similar nas respostas dos sujeitos do município de Iguape para a questão; como se chama “... a inflamação no olho que faz com que o olho fique vermelho e amanheça grudado?".

$\mathrm{O}$ item lexical de maior frequência, em Iguape, para essa questão, foi “conjuntivite" (41,67\%), seguido do item lexical "dordolhos" (25\%). Cabe observar que todos os sujeitos que responderam "conjuntivite" pertenciam à primeira faixa etária, ou seja, a mais jovem. Quanto ao uso do item lexical "dordolhos”, registrou-se que foram respostas dadas exclusivamente por sujeitos da segunda faixa etária.

Silveira (2009) afirma que existe uma tendência à escolha, por sujeitos da primeira faixa etária, de termos técnicos. Se considerarmos a área semântica "corpo humano", podemos perceber, em Iguape, termos de especialidade usados, predominantemente, por sujeitos da primeira faixa etária.

Segundo Silveira (2009, p. 84), 


\begin{abstract}
A preferência do uso do termo técnico-científico pelos sujeitos da primeira faixa etária é patente, ao contrário do que ocorre com os sujeitos da segunda faixa etária. Essa geração, provavelmente, teve mais acesso aos programas de saúde do governo, refletindo-se essa situação no vocabulário, enriquecido desses termos. Também essa geração passou mais anos na escola, o que deve ter ampliado seu vocabulário vernáculo.
\end{abstract}

Essa escolha de termos mais técnicos pela primeira faixa etária pode estar relacionada à interação e ao contexto social no qual os itens lexicais foram atualizados, ou seja, o fato de a interação ter ocorrido na forma de uma entrevista, pode ter induzido os sujeitos a buscarem itens lexicais que permitissem maior formalidade.

Nas interações verbais do dia-a-dia, os interlocutores, numa conversa, se baseiam em conhecimentos e estereótipos relativos a diferentes maneiras de falar (GUMPERZ, 2002).

Para Blom e Gumperz (2002, p. 83-4),

A simples observação naturalista do comportamento verbal não basta. A fim de interpretar o que ouve, o investigador deve possuir algum conhecimento prévio da cultura local e dos processos que geram o significado social. Sem isso, é impossível fazer generalizações sobre as implicações sociais das diferenças dialetais.

Qualquer forma de comportamento, verbal ou não-verbal, deve ser apropriada nos diversos contextos sociais. Diante disso, a maneira como o sujeito se vê socialmente e a maneira como vê o seu interlocutor são preponderantes para as escolhas, tanto lexicais quanto estruturais, que ele faz no momento da interação. As relações sociais atuam como uma variável que intervém entre as possibilidades linguísticas e suas realizações na fala.

\title{
Considerações finais
}

A pesquisa sociogeolinguística prioriza a variação diatópica. Contudo, cabe ressaltar que atualmente à variável diatópica, num dado ponto do espaço escolhido, aliam-se as variáveis de gênero, faixa etária e escolaridade. Assim, evidencia-se um 
trabalho que permite uma série de análises, além da apresentação de resultados em cartogramas linguísticos que, compilados, constituem-se no Atlas Linguístico da localidade estudada.

Entre outras possibilidades de reflexão, encontra-se a análise do uso de itens lexicais que assumem formas em desuso ou em inovações, podendo retratar as transformações por que passa a sociedade.

Ao observarmos, nos trabalhos pesquisados para este artigo, que os itens lexicais "pinguela" e "dordolhos" são usos exclusivos da segunda faixa etária, ou seja, de sujeitos de 50 a 65 anos de idade, podemos inferir que há uma mudança em curso e que esses itens lexicais podem estar se encaminhando a uma classificação como arcaísmos num futuro próximo.

É importante ressaltar que essa análise é uma das possibilidades que a abordagem sociogeolinguística possibilita, pois, no momento em que amplia as variáveis para a pesquisa, o estudo possibilita análises que visam a um conhecimento mais específico das variações linguísticas e a uma aproximação com os integrantes dos variados grupos sociais para, com eles, estabelecer um diálogo, uma interação, e compreender melhor a causa dessas diferenças, resultantes de operações de forças sociais, envolvendo grupos étnicos, religiosos, educacionais, econômicos e outros.

\section{Referências}

BLOM, J.; GUMPERZ, J. J. O significado social na estrutura linguística: Alternância de códigos na Noruega In: RIBEIRO, B. T.; GARCEZ, P. M. (Orgs.). Sociolinguística Interacional. São Paulo, Loyola, 2002, p. 45-84.

CRISTIANINI, A. C. Atlas semântico-lexical da região do Grande ABC. 2007. Tese (Doutorado em Linguística) - Faculdade de Filosofia, Letras e Ciências Humanas, Universidade de São Paulo, São Paulo, 2007.

CRISTIANINI, A. C. Sociogeolinguística: uma abordagem para o estudo do léxico. In: SANTOS, I. P.; CRISTIANINI, A. C. Sociogeolinguística em questão: reflexões e análises. São Paulo: Paulistana, 2012, p. 21-32.

CRISTIANINI, A. C.; ENCARNAÇÃO, M. R. T. da. A contribuição dos estudos sociogeolinguísticos para a escolha lexical na recepção e produção de textos orais $\mathrm{e}$ 
escritos. In: CONGRESSO NACIONAL DE LINGUÍSTICA E FILOLOGIA, XII, 2008, Rio de Janeiro. Livro dos Mini cursos - Cadernos do CNFL. Rio de Janeiro: Círculo Fluminense de Estudos Filológicos e Linguísticos, 2009. v. XII. p. 10-17.

ENCARNAÇÃO, M. R. T. da. Atlas semântico-lexical de Caraguatatuba, Ilhabela, São Sebastião e Ubatuba - municípios do Litoral Norte de São Paulo. 2010. Tese (Doutorado em Linguística) - Faculdade de Filosofia, Letras e Ciências Humanas, Universidade de São Paulo, São Paulo, 2010.

GUMPERZ, J. J. Convenções de contextualização. In: RIBEIRO, B. T.; GARCEZ, P. M. (Orgs.). Sociolinguística Interacional. São Paulo, Loyola, 2002, p. 149-182.

MORAES, M. C. O Paradigma educacional emergente. 6. ed. Campinas: Papirus, 2001.

MORIN, E. A inteligência da complexidade. Tradução de Nurimar Maria Falci. São Paulo: Peirópolis, 2000.

SANTOS, I. P. O léxico paulistano no contexto da lusofonia: aspectos discursivos. In: 8o. Colóquio Anual da Lusofonia, 2009, Bragança, Portugal. Atas/Anais do 80. Colóquio Anual da Lusofonia. Bragança, 2009. p. 205-215.

SILVEIRA, R. Estudo sociogeolinguístico do município de Iguape: aspectos semântico-lexicais. 2009. Dissertação (Mestrado em Linguística) Faculdade de Filosofia, Letras e Ciências Humanas, Universidade de São Paulo, São Paulo, 2009.

Artigo recebido em: 30.03 .2012

Artigo aprovado em: 30.04 .2012 